\title{
CAPSULE COMMENTARIES \\ Capsule Commentary on Okoro et al., Effects of Massachusetts Health Reform on the Use of Clinical Preventative Services
}

\author{
Jennifer Merlo Schmidt, MD \\ Department of Internal Medicine, Medical College of Wisconsin and the Zablocki VAMC, Milwaukee, WI, USA.
}

J Gen Intern Med 29(9):1270

DOI: $10.1007 / \mathrm{s} 11606-014-2887-9$

(c) Society of General Internal Medicine 2014

$\mathrm{T}$ his study by Okoro et al. ${ }^{1}$ examined whether Massachusetts' health reform was associated with changes in healthcare access and use of clinical preventative services. They found that the proportion of adults with health insurance, a healthcare provider, annual routine checkup and colorectal cancer screening were significantly increased after Massachusetts' health reform was initiated when compared with surrounding New England states. No differences in rates of breast cancer, cholesterol screens and influenza vaccines were noted pre and post-health reform. The authors conclude that health reform may increase access to healthcare and clinical preventative services.

This article shows that access to insurance does lead to increased utilization of healthcare, and increase in some, but not all preventive services. Insurance is only one piece of the solution. The uninsured utilize preventative care 10 $30 \%$ less than the general population. However, across the United States, less than $75 \%$ of those with insurance use preventative services. $^{2}$ The rates of preventive services was higher in Massachusetts as well as the surrounding New England states than the rest of the United states, with $90 \%$ having had breast cancer, cervical cancer and cholesterol screening. In New England, there appears to be more than insurance accounting for high levels of preventive service utilization. While insurance will lead to increased utilization of healthcare elsewhere, this alone will not ensure higher rates of preventative services and the differences according to this study will be small.

Alternative approaches to care delivery might help. For example, the medical home may help minimize healthcare disparities and increase access to primary care and preventative services. ${ }^{3}$ Low-income adults served by a medical home and with insurance are nearly as likely as those with higher- incomes to receive preventative care services. ${ }^{4}$ Full implementation of this model awaits development of payer models. Pay for performance might also serve to increase utilization of preventive services if properly incentivized. Benchmarking performance in preventive services has also been shown to increase their use. Careful design and use of performance measures may help improve preventive health care. ${ }^{5}$

To increase preventative care access, insurance is necessary, but needs to be coupled with regular primary care and stakeholder accountability. ${ }^{4}$ Further research into what incentivizes patients to get primary care and physicians to ensure comprehensive preventative care is needed as healthcare reform continues.

Conflict of Interest: The author has no conflict with any of the material in this manuscript.

Corresponding Author: Jennifer Merlo Schmidt, MD; Department of Internal Medicine, Medical College of Wisconsin and the Zablocki VAMC, Milwaukee, WI, USA (e-mail: jmschmidt@mcw.edu).

\section{REFERENCES}

1. Okoro CA, Dhingra SS, Coates RJ, Zack M, Simoes EJ. Effects of Massachusetts Health Reform on the Use of Clinical Preventative Services. J Gen Intern Med. 2014; SPI \#2865.

2. "Conclusions and Future Directions for Periodic Reporting on the Use of Selected Adult Clinical Preventive Services-United States." Centers for Disease Control and Prevention. Centers for Disease Control and Prevention, 15 June 2012.

3. Grant R, Greene D. The health care home model: primary health care meeting public health goals. Am J Public Health. 2012;102:1096-1103. doi:10.2105/AJPH.2011. 300397.

4. Berenson J, Doty MM, Abrams MK, Shih A. Achieving better quality of care for low-income populations: the roles of health insurance and the medical home for reducing health inequities. The Commonwealth Fund, May 2012. http://www.commonwealthfund.org/Publications/IssueBriefs /2012/May/Achieving-Better-Quality-of-Care-for-Low-IncomePopulations.aspx. Accessed 12 May 2014.

5. Baker DW, Gaseem A, Reynolds PP, Gardner LA, Schneider ED. Design and use of performance measures to decrease low-value services and achieve cost-conscious care. Ann Intern Med. 2013;158(1):55-59.

Published online May 15, 2014 